\title{
Synthesis and Characterization of Thermo-sensitive Poly(L-lactide-co-morpholine-2,5-dione)
}

\author{
Akoda Komlan Elom ${ }^{1}$, Ziming Yin ${ }^{1}$, Zhihui Fan ${ }^{1}$, Chang Zheng ${ }^{1}$, Jihua Song ${ }^{1}$ \\ ${ }^{1}$ College of Chemistry \& Environmental Science, Hebei University, Baoding 071002, China \\ Tel: +86-0312-5971137; Fax: +86-0312-5079525; E-mail: akodakomlanelom@yahoo.fr
}

\begin{abstract}
Keywords: morpholine-2,5-dione, L-lactide, thermo-sensitivity, biocompatibility
Abstract: Poly(L-lactide-co-morpholine-2,5-dione) (PLAMD) was synthesized via ring-opening polymerization (ROP) of morpholine-2,5-dione and $L$-lactide using stannous octoate as initiator. Poly (L-lactide-co-morpholine-2,5-dione) was characterized by means of ${ }^{1} \mathrm{H}$ NMR, FTIR spectrum and gel permeation chromatography (GPC). Poly(L-lactide-Co-morpholine-2,5-dione) shows a reversible upper critical solution temperature (UCST) of $18-35{ }^{\circ} \mathrm{C}$, and the thermo-sensitivity is affected by its structure and concentration. The viability of HeLa cells in $0.01-50 \mu \mathrm{g} / \mathrm{mL}$ of polymer solution was found to be in a range of $70-85 \%$ after $48 \mathrm{~h}$ incubation. To sum up, this new thermo-sensitive polymer has excellent biocompatibility, which makes it a promising material in the biomedical fields.
\end{abstract}

\section{Introduction}

Polylactides (PLAs) derived lactide or lactic acid monomers has been extensively investigated over the last several decades [1]. PLAs and their copolymers become the most important and promising aliphatic polyesters in the biomedical fields because of their excellent biocompatibility and non-toxicity. And also, PLAs can bio-degrade by the metabolization in the body so as to the materials show no retrieval of the device after usage [2]. The increasing use of biodegradable polymers in the medicine application fields including as implant materials for bone fixation [3], drug delivery systems [4-5], surgical surture [6] has expanded into the new material with potential applications. For example, the main focus of these studies is the controlled degradation behavior and mechanical performance about PLAs materials. Although PLA is an eco-friendly biomaterial, its drawbacks exist especially as functional scaffolds leading to aching pain and even inflammation for related tissue. As natural biomolecules, amino acids can be used to improve the biocompatibility and other desired performances of PLA material by copolymerization of amino acids with lactide or lactic acid monomers. In this paper, we reported the synthesis of morpholine-2,5-dione, ring-opening polymerization of morpholine-2,5-dione with lactide acid. And also, we investigated the responsiveness to temperature and biocompatibility of poly(L-lactide-Co-morpholine-2,5-dione) by MTT method.

\section{Experiment}

Materials. $L$-lactide (AP), morpholine-2,5-dione (AP), acetic ester, dimethyl formamide (AP) and triethylamine (AP) were purchased from Shanghai. Chemical Reagent Company, and composite oxide catalyst (prepared in our lab) and stannous octoate (CP) were purchased from Sigma Company.

Synthesis of poly(L-lactide-co-morpholine-2,5-dione) (PLAMD). A certain amount of morpholine-2,5-dione $(0.3 \mathrm{~g}, 2.6 \mathrm{mmol})$ and $L$-lactide $(0.188 \mathrm{~g}, 1.3 \mathrm{mmol})$ were mixed evenly with $\operatorname{DMF}(0.5 \mathrm{~mL})$ and put into a flask $10 \mathrm{~mL}$ ( two monomer of the molar ratio was 0.5:1). The reaction system was stirred and warmed up to $140{ }^{\circ} \mathrm{C}$ for several times under gases of nitrogen. Then DMF $(0.15 \mathrm{~mL})$ solution with stannous octoate $(1 \%)$ was added as an initiator. Then the flask was kept in under gases of nitrogen at $160{ }^{\circ} \mathrm{C}$ for $12 \mathrm{~h}$ before being precipitated into ethanol, the brown yellow sample(PLAMD) was dried under reduced pressure to yield a yellow solide. IR( $\left.\mathrm{cm}^{-1}, \mathrm{KBr}\right): 3392$ $(\mathrm{N}-\mathrm{H}), 2995(\mathrm{C}-\mathrm{H}), 1757(\mathrm{C}=\mathrm{O}), 1681(\mathrm{C}=\mathrm{O}), 1541(\mathrm{~N}-\mathrm{H}), 1185(\mathrm{C}-\mathrm{O}-\mathrm{C}) .{ }^{1} \mathrm{H}$ NMR (ppm, DMSO-d $\left.)_{6}\right)$ : $\delta=8.55(\mathrm{~s}, 1 \mathrm{H}), \delta=5.21(\mathrm{~s}, 1 \mathrm{H}), \delta=4.59(\mathrm{~s}, 2 \mathrm{H}), \delta=4.03(\mathrm{~s}, 2 \mathrm{H}), \delta=1.47(\mathrm{~d}, 3 \mathrm{H})$. 


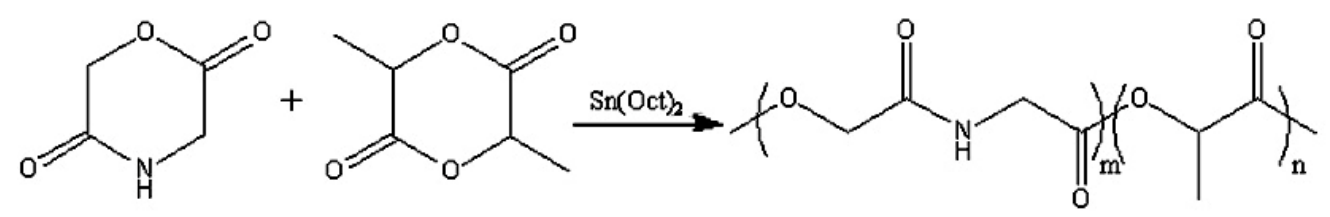

Fig. 1 The synthesis process of poly( $L$-lactide-co-morpholine-2,5-dione $)$

\section{Results and Discussion}

Characterization of thermo-sensitive PLAMD. Fig. 2 Shows the IR spectrum of the prepared $\operatorname{poly}(L$-lactide-co-morpholine-2,5-dione), with the ratio of $L$-lactide to morpholine-2,5-dione as $0.5: 1$. The peak at $3392 \mathrm{~cm}^{-1}$ originates from the stretching vibration of amide $(\mathrm{N}-\mathrm{H})$. The peaks centered at $2995 \mathrm{~cm}^{-1}$ originate from the stretching vibration of methyl $\left(\mathrm{CH}_{3}\right)$. The peak at $1757 \mathrm{~cm}^{-1}$ was ascribed to the stretching vibration of $\mathrm{C}=\mathrm{O}$ of ester bond. The peak at $1681 \mathrm{~cm}^{-1}$ originates from the stretching vibration of amide I, and the peak centered at $1541 \mathrm{~cm}^{-1}$ was attributed to the stretching vibration of amide II. The peaks at $1835 \mathrm{~cm}^{-1}$ originate from the bending vibration of ether (-C-O-C-). The vibration intensity of $\mathrm{C}=\mathrm{O}$ is much higher than that of amide $\mathrm{I}$. As the ratio of $L$-lactide to morpholine-2,5-dione as $0.5: 1$, the copolymerization of $L$-lactide and morpholine-2,5- dione was performed and polymer was characterized by NMR measurement. As shown in Fig. 3, the ${ }^{1} \mathrm{H}$ NMR peak at about $4.59 \mathrm{ppm}$ and $4.03 \mathrm{ppm}$ were assigned to $\mathrm{OCH}_{2}$ protons and $\mathrm{NHCH}_{2}$ protons of morpholine-2,5-dione unit, respectively. The peak at $8.55 \mathrm{ppm}$ was assigned to protons of nitrogen in amide group, and the peaks at about $1.47 \mathrm{ppm}$ was assigned to methyl protons of DMSO- $d_{6}$. The peak at $5.21 \mathrm{ppm}$ was assigned to methylene protons of $L$-lactide. All the ${ }^{1} \mathrm{H}$ NMR data suggests that the copolymerization of lactide and morpholine-2,5-dione is successful.

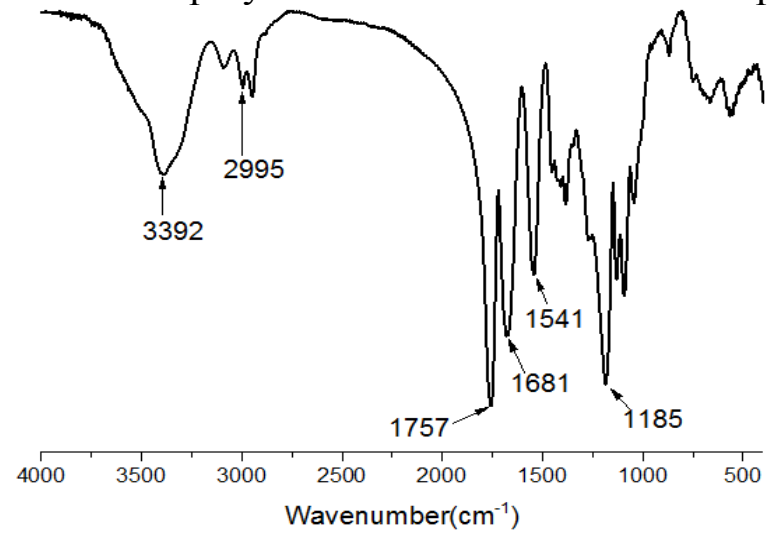

Fig.2 FTIR spectrum of PLAMD

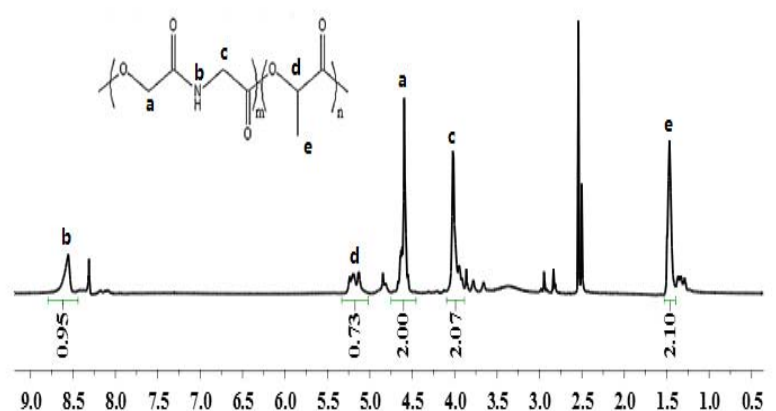

Fig. $3{ }^{1} \mathrm{H}$ NMR spectrum of PLAMD( DMSO- $d_{6}$ )

In this investigation, we prepared the polymer with different molecular weights by changing the mole ratio of two monomers. Three ratios of $L$-lactide to morpholine-2,5-dione were selected in the synthesis of PLAMD. The detail experimental results were summarized in Tab. 1. The Mn of PLAMD reaches its highest value $\left(\mathrm{Mn}=1.02 \times 10^{4} \mathrm{~g} \cdot \mathrm{mol}^{-1}\right)$, when the ration of lactide to morpholine-2,5-dione equals 1:1. However the molecular weights of PLAMD decreasse to $1.02 \times 10^{4}$

Tab. 1 Ring-opening polymerization of morpholine-2,5-dione and $L$-lactide)

\begin{tabular}{llllll}
\hline $\begin{array}{l}\text { Samples } \\
\text { item }\end{array}$ & $\begin{array}{l}\text { PLAMD } \\
\text { (molar ratio) }\end{array}$ & $\begin{array}{l}\text { PLAMD } \\
\text { (structural units) }\end{array}$ & $\operatorname{Mn}\left(\times 10^{4}\right)$ & $M \mathrm{n} / \mathrm{Mw}$ & $\mathrm{UCST}$ \\
\hline 1 & $0: 1$ & $0: 1$ & - & - & $\times$ \\
2 & $0.25: 1$ & $0.125: 1$ & 0.88 & 1.27 & $\times$ \\
3 & $0.5: 1$ & $0.35: 1$ & 0.90 & 1.25 & $\sqrt{ }$ \\
4 & $0.75: 1$ & $0.6: 1$ & 0.96 & 1.28 & $\sqrt{ }$ \\
5 & $1: 1$ & $0.8: 1$ & 1.02 & 1.26 & $\sqrt{ }$
\end{tabular}


\begin{tabular}{rrr}
6 & $1: 0$ & $1: 0$ \\
\hline
\end{tabular} and $0.9 \times 10^{4}{\mathrm{~g} . \mathrm{mol}^{-1}}^{-1}$ as the ratios of $L$-lactide to morpholine-2,5-dione were fixed at 1:1, $0.75: 1$, $0.5: 1$, respectively. Through experiments, the structural unit ratio $L$-lactide to morpholine-2,5-dione in PLAMD was found to be $0.8 \sim 0.1: 1$. Some PLAMD can show temperature-sensitive properties to the external temperature.

UCST of PLAMD material. We have demonstrated that PLAMD can display thermo-responsive behaviors in water. Thus, the optical transmittance of a light beam at $600 \mathrm{~nm}$ through the sample cell of the spectrometer was monitored as a function of temperature. Typical transmittance versus temperature plots resulting from turbidimetry were shown in Fig. 4, for PLAMD solution (concentration of $\mathrm{c}=0.5 \mathrm{WT}$. \%) can repeat reversible phase transition.

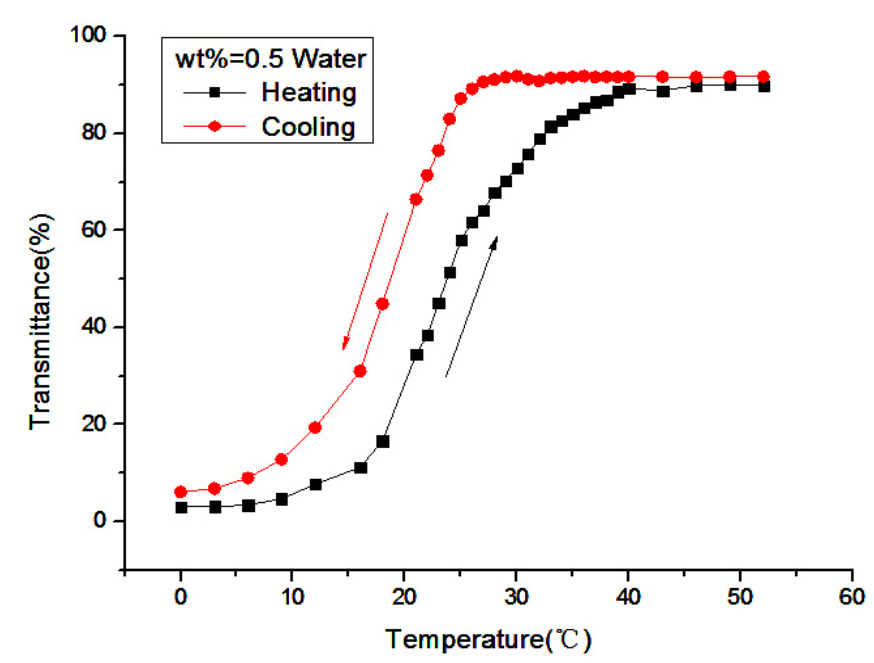

Fig. 4 The phase transformation curve of PLAMD

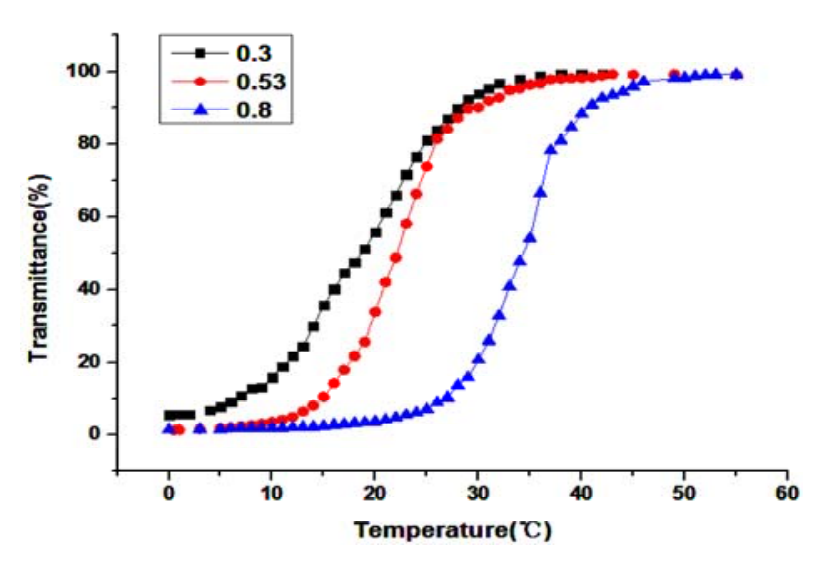

(a)

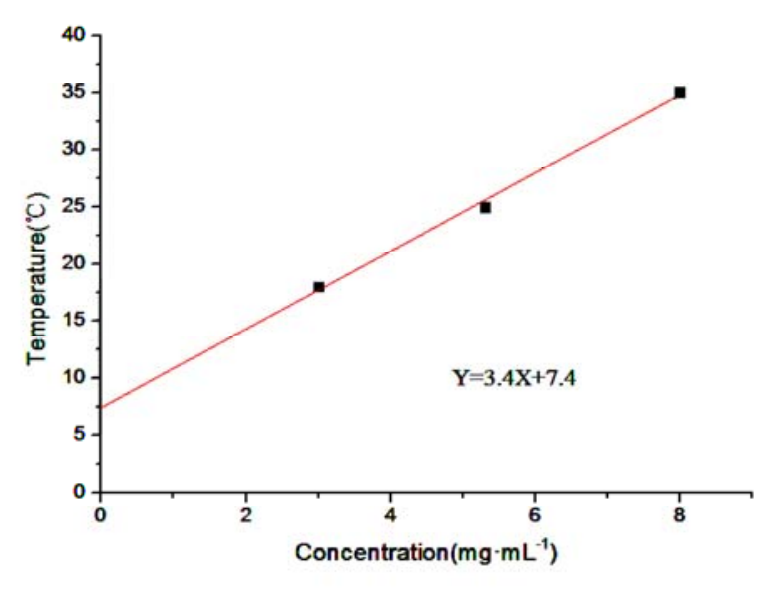

(b)

Fig. 5 The influence of different PLAMD solution concentration on UCST.

The upper critical solution temperatures (UCSTs) were observed as during the cooling runs at $23.5^{\circ} \mathrm{C}$, a sharp transition from high transmittance (about $100 \%$ ) to low transmittance (about $0 \%$ ) was detected indicating phase separation of the solution and the aggregation of the copolymer. Similarly, a reversed transition from low transmittance to high transmittance was also recorded during heating, indicating dissolution of the copolymer. Therefore, The phase transition temperature of PLAMD increased from $18.5{ }^{\circ} \mathrm{C}, 25.6{ }^{\circ} \mathrm{C}$, to $35.2{ }^{\circ} \mathrm{C}$ as the concentration increased from $0.3 \%$, and $0.53 \%$, to $0.8 \%$ in Fig. 5(a). In fact, the UCST of polymer structure, molecular weight of polymer, solvent decided by such factors as the real UCST can be according to the experiment of the relationship between apparent UCST and polymer concentration extrapolation. As shown in Fig. 
$5(b)$, based on the extrapolation of the polymer concentration and the UCST, polymer can be obtained extrapolation USCT at $7.4{ }^{\circ} \mathrm{C}$.

Cytotoxicity evaluation for PLAMD. In addition, the cell cytotoxicity of PLAMD was evaluated using MTT method. HeLa cells were exposed to the different concentration of PLAMD for 24 and $48 \mathrm{~h}$ cultivation. As shown in Fig. 6 . When the concentration of PLAMD varied between 0.01 and $50 \mu \mathrm{gmL}^{-1}(0.01,0.1,1,10,50 \mu \mathrm{g} / \mathrm{mL})$, the cell viability reached up to $70 \%$ after 24 and $48 \mathrm{~h}$ incubation. Even for the $50 \mu \mathrm{g} / \mathrm{mL}$ PLAMD solution, the cell viability after $48 \mathrm{~h}$ incubation is more than $70 \%$. These results indicated no obvious cytotoxicity against HeLa cells in the presence of the synthesized PLAMD. The absence of cytotoxicity suggests that PLAMD is a potential candidate for a wide range of biomedical application.

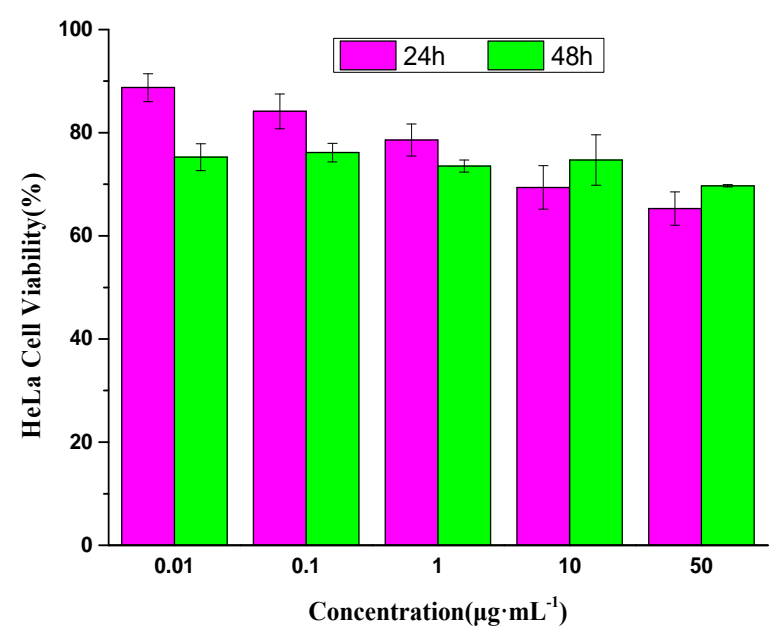

Fig. 6 HeLa cell viability in different concentration of PLAMD solution

\section{Conclusions}

We have described a new thermo-sensitive PLAMD with no cytotoxicity and tunable UCST phase transition. The UCST depends on the polymer concentration and Mn, it is facile to get tunable UCST between $18.5^{\circ} \mathrm{C}$ and $35.2{ }^{\circ} \mathrm{C}$ in water. As a new polymer with a UCST, the reversible phase transition of PLAMD is driven by the intra and intermolecular $\mathrm{H}$ bonds. The repeating unit, $L$-lactide and morpholine-2,5-dione, endow the thermo-sensitive polymer with no cytotoxicity, implying its potential application in the field of biomedicine.

\section{Acknowledgements}

This work was supported by Hebei Natural Science Foundation of China (B2015201133)

\section{References}

[1] X.B. Cao, Y.L. Wang, J. Pan, X. Lu and S.X. Cai: Polymer Materials Science and Engineering. Vol. 18(2002), p.115

[2] J.E. Bergsma, F.R. Rozema, R.M. Bos, G. Boering, W.C. Bruijn And A. Pennings: J Biomaterials. Vol. 16(1995), p.247

[3] J.E. Bergsma, R. R. M Bos, F.R. Rozema, W.D. Jong and G. Boering: J Mater Sci: Mater Med Vol. 7(1996). P.1

[4] K.L. Zhu, X.Z. Lin and S.L. Yang: J Appl PolymSci. Vol. 39(2009), p.1

[5] Y.L. Di, X. Ma, C.X. Li, H.M. Liu, X.Y. Fan, M. Wang, H.Y. Deng, T. Jiang, Z.M. Yin, K.L Deng: Macromol Chem Phys. Vol. 215(2014), P.365

[6] L. Fambri, A. Pegoretti, R. Fenner, S.D. Incardona, C. Migliarisi: Polymer. Vol. 38(1997), p. 79 